Postprint

THE WELLEK LIBRARY LECTURES 


\title{
THE WELLEK LIBRARY LECTURES
}

The Wellek Library Lectures in Critical Theory are given annually at the University of California, Irvine, under the auspices of UCI Critical Theory. The following lectures were given in May 2016.

\author{
UCI Critical Theory \\ James A. Steintrager, Director
}

For a complete list of titles, see page 23I 
N. Katherine Hayles
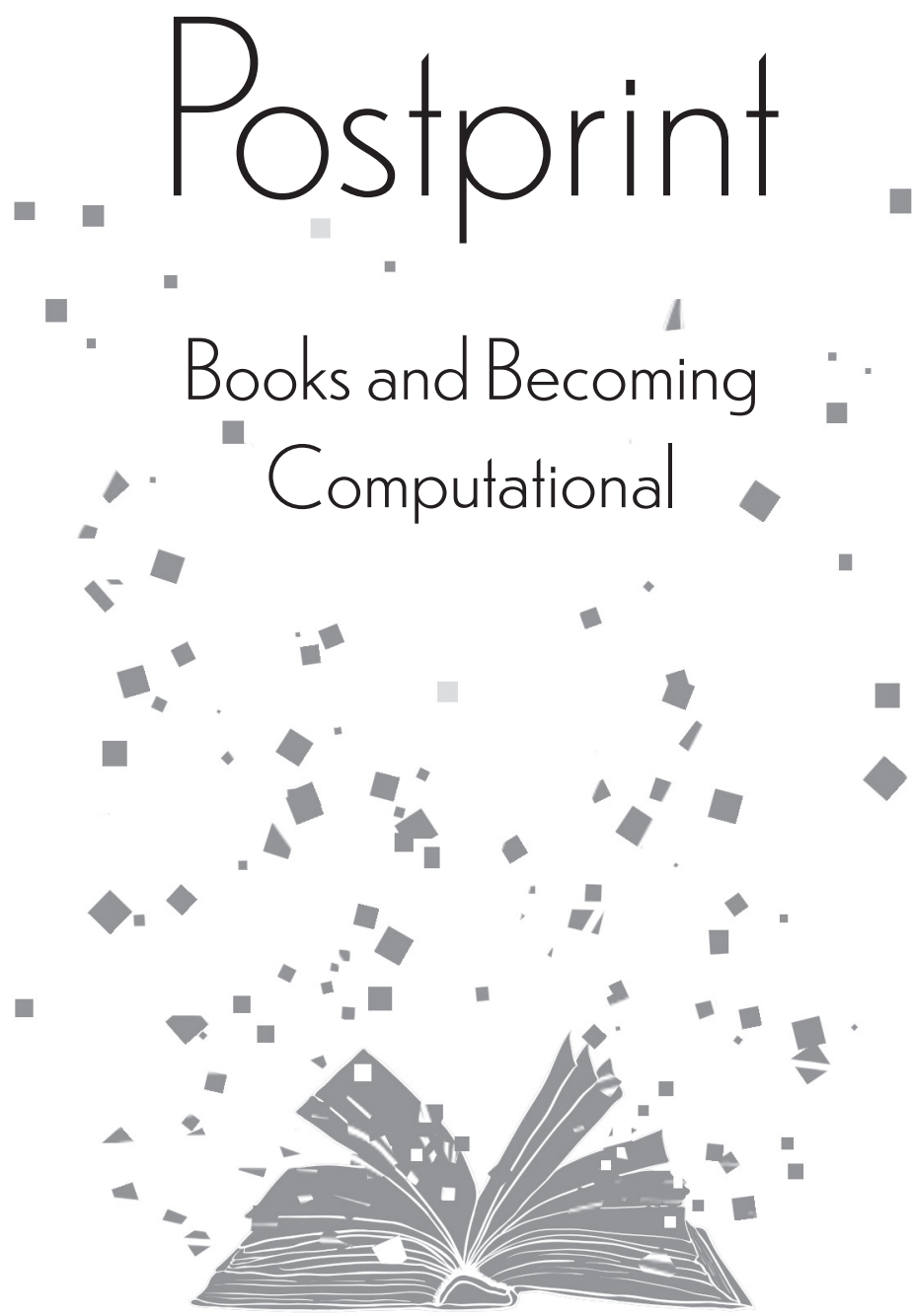

Columbia University Press Nerw York 


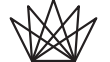 \\ Columbia University Press \\ Publishers Since 1893 \\ New York Chichester, West Sussex \\ cup.columbia.edu \\ Copyright (C) 202I Columbia University Press \\ All rights reserved}

Library of Congress Cataloging-in-Publication Data

Names: Hayles, N. Katherine, 1943- author.

Title: Postprint : books and becoming computational /

N. Katherine Hayles.

Description: New York : Columbia University Press, [2020] |

Series: The Wellek Library lectures | Includes bibliographical references and index.

Identifiers: LCCN 20200224IO (print) | LCCN 20200224II (ebook)

| ISBN 978023II98240 (hardcover) | ISBN 978023 II98257

(trade paperback) | ISBN 9780231552554 (ebook)

Subjects: LCSH: Book industries and trade-Technological innovations. | Book industries and trade-Social aspects. | Digital

media-Social aspects. | Cognition. | Communication and technology.

Classification: LCC Z 278 .H39 2020 (print) | LCC Z 278 (ebook) |

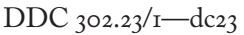

$\mathrm{LC}$ record available at https://lccn.loc.gov/20200224IO

LC ebook record available at https://lccn.loc.gov/20200224II

Columbia University Press books are printed on permanent and durable acid-free paper.

Printed in the United States of America

Cover image: Digital composite

Cover design: Lisa Hamm 